\title{
Induction of galectin-I expression by HTLV-I Tax and its impact on HTLV-I infectivity
}

\author{
Sonia Gauthier ${ }^{1}$, Isabelle Pelletier ${ }^{1}$, Michel Ouellet ${ }^{1}$, Amandine Vargas ${ }^{2}$, \\ Michel J Tremblay ${ }^{1}$, Sachiko Sato ${ }^{1}$ and Benoit Barbeau*2
}

\author{
Address: ${ }^{1}$ Research Center in Infectious Diseases, CHUL Research Center, 2705 boul. Laurier; Ste-Foy, Québec, G1V 4G2, Canada and ${ }^{2}$ Université \\ du Québec à Montréal, Département des sciences biologiques, 2080 St-Urbain, Montréal, Québec, H2X 3X8, Canada \\ Email: Sonia Gauthier - sonia.gauthier@crchul.ulaval.ca; Isabelle Pelletier - isabelle.pelletier@crchul.ulaval.ca; \\ Michel Ouellet - michel.ouellet@crchul.ulaval.ca; Amandine Vargas - amandine.vargas@voila.fr; \\ Michel J Tremblay - michel.j.tremblay@crchul.ulaval.ca; Sachiko Sato - sachiko.sato@crchul.ulaval.ca; \\ Benoit Barbeau* - barbeau.benoit@uqam.ca \\ * Corresponding author
}

Published: 25 November 2008

Retrovirology 2008, 5:105 doi:10.1 186/1742-4690-5-105

This article is available from: http://www.retrovirology.com/content/5/I/I05

C) 2008 Gauthier et al; licensee BioMed Central Ltd.

This is an Open Access article distributed under the terms of the Creative Commons Attribution License (http://creativecommons.org/licenses/by/2.0), which permits unrestricted use, distribution, and reproduction in any medium, provided the original work is properly cited.

\begin{abstract}
Background: Cell-free Human T-cell Leukemia Virus type I (HTLV-I) virions are poorly infectious and cell-to-cell contact is often required to achieve infection. Other factors might thus importantly contribute in increasing infection by HTLV-I. Galectin-I is a galactoside-binding lectin which is secreted by activated $\mathrm{T}$ lymphocytes. Several functions have been attributed to this protein including its capacity to increase cell-to-cell adhesion. Based on previous studies, we postulated that this protein could also accentuate HTLV-I infection.
\end{abstract}

Results: Herein, we demonstrate that galectin-I expression and release are higher in HTLV-Iinfected $T$ cells in comparison to uninfected $T$ cells. Furthermore, galectin-I expression was activated in various cell lines expressing the wild type viral Tax protein while this induction was minimal upon expression of NF- $\mathrm{KB}$ activation-defective TaxM22. Cotransfection of these Tax expression vectors with galectin-I promoter-driven luciferase constructs confirmed that Tax upregulated galectin-I promoter activity. However, a NF-KB-independent mechanism was strongly favoured in this induction of galectin-I expression as no activation of the promoter was apparent in Jurkat cells treated with known NF-KB activators. Using HTLV-I envelope pseudotyped HIV-I virions, galectin-I was shown to increase infectivity. In addition, a co-culture assay with HTLV-Iinfected cells also indicated an increase in cell fusion upon addition of galectin-I. This effect was not mediated by factors present in the supernatant of the HTLV-I-infected cells.

Conclusion: These data suggest that HTLV-I Tax increases galectin-I expression and that this modulation could play an important role in HTLV-I infection by stabilizing both cell-to-cell and virus-cell interactions.

\section{Background}

Human T-cell Leukemia Virus type I (HTLV-I) is the etiological agent of adult T cell leukemia (ATL) and HTLV-Iassociated myelopathy/tropical spastic paraparesis
(HAM/TSP) [1-3]. It has been estimated that 20 million individuals are infected worldwide [4]. The in vivo target cells are mature CD4+CD45RO T lymphocytes and CD8+ $\mathrm{T}$ lymphocytes [5], although other cell types have been 
suggested to be potential target including lung epithelial cells, as recently demonstrated [6]. HTLV-I is transmitted between individuals by the transfer of infected lymphocytes and is thought to require repeated contacts as only one out of $1 \times 10^{5}$ to $1 \times 10^{6}$ viruses is infectious [79]. During viral transmission, a contact is established between an uninfected and an infected $\mathrm{T}$ cell by the interaction of the gp 46 viral protein with its cellular receptor subsequently followed by the polarization of the infected cell cytoskeleton at the site of cell-to-cell contact and the accumulation of viruses at the cell junction [7]. GLUT-1 has been reported to be part of this receptor and to be involved in the first step of viral entry, although its exact role is still ill-defined [10,11]. Although the cellular ICAM-1 protein has been established as a potential inducer of microtubule reorganization, the viral Tax protein has also been shown to be active in this process $[12,13]$.

Tax is the viral transactivator of HTLV-I allowing transcription through the three Tax-responsive elements (TRE1) present in the U3 region of the Long Terminal Repeat (LTR) [14-16]. This viral protein also promotes transcription of many cellular genes. To activate transcription, Tax does not bind directly to the different cellular and viral promoters but forms complexes with transcription factors, such as the cAMP Response Element Binding transcription factor (CREB). In uninfected cells, CREB phosphorylation leads to its interaction with CBP (CREBbinding protein) and the recruitment of the transcriptional machinery to CRE elements. In HTLV-I infected cells, Tax binds simultaneously to CBP and CREB and recruits the complex to viral TRE1 allowing constitutive LTR-dependent transcription [17]. Several studies have also provided detailed analysis on the mechanism of Taxmediated activation of NF- $\mathrm{KB}$ by its association to IKK and upstream kinases [18]. Modulation of cellular genes by Tax has been extensively studied and has been shown to involve various transcription factors. In a previous study, using high-density gene arrays, 763 genes were shown to have differential gene expression profiles in HTLV-I-transformed and immortalized cell lines compared to peripheral blood mononuclear cells (PBMCs) [19]. One of the genes from which the expression was upregulated corresponded to the mammalian soluble $\beta$-galactoside-binding lectin, galectin-1 (LGALS1).

Galectins are a phylogenetically conserved family of proteins, present from invertebrates to mammals [20-22]. This family is constituted of at least 14 different galectins, most of which have an affinity for $\beta$-galactoside containing glycoconjugates, such as lactosamine residues $[20,23]$. The galectin family is further subdivided into three subfamilies: the prototype, the tandem repeat and the chimera groups [20]. Galectin-1 is a member of the prototype subfamily. While galectin-1 is primarily synthesized as a monomer that has one carbohydrate recognition domain (CRD), it also forms a dimer, which thus has the capacity to bind to two different $\beta$-galactoside-containing ligands. Galectin-1 is present in the cytoplasm of many cell types but can also be secreted [24-26]. Indeed, although nascent galectin-1 does not contain any signal sequence or hydrophobic domain necessary for usage of the secretory pathway, it has been well established that certain type of cells, such as activated $\mathrm{T}$ cells and thymus epithelial cells, secrete this lectin through a leaderless secretion pathway without compromising membrane integrity $[22,24-28]$. The expression of the galectin-1 gene is modulated during cellular differentiation and transformation [22,29]. Its expression is controlled by DNA methylation [30,31], known to restrict the access of transcription factors to binding sites [32]. The $+1 /+30$ region of the galectin- 1 gene is well preserved between different species [33] and the upstream $(-57 /-31)$ and downstream elements $(+10 /$ $+57)$ of the initiation site account for the majority of the basal promoter activity [34]. However, little information is available on the transcription factor(s) involved in the modulation of the expression of this gene.

Being a dimer, galectin-1 could mediate cell-cell or cellpathogen interactions. Indeed, our recent report suggests that galectin-1 stabilizes HIV-1 binding to its target, activating $\mathrm{CD} 4+\mathrm{T}$ lymphocytes and therefore promoting HIV-1 infectivity $[35,36]$. Since an early report has suggested that HTLV-I-infected cells express galectin-1 [19] and HTLV-I infection requires cell-cell contact for several cell types, we investigated the pattern of expression of galectin-1 in infected cells and its possible impact on HTLV-I transmission. Our data show that Tax significantly induces transcription from the galectin-1 promoter in an NF-אB-, SRF- and CREB-independent manner. In fact, cell lines chronically infected by HTLV-I release more galectin1 when compared to non-infected $\mathrm{T}$ cell lines. Furthermore, soluble galectin-1 increases HTLV-I cellular infection by HTLV-I gp46-pseudotyped HIV-1 virions. In addition, our data suggest that soluble galectin-1 enhances HTLV-I-mediated cell fusion between chronically infected cells and uninfected cells.

\section{Methods \\ Cell culture and reagents}

The following HTLV-I-infected cell lines were used in this study: C8166-45 [37], C91-PL [38], MJ [39], MT2 [40] and S1T [41]. The non-infected T cell lines, A2.01 [42], CEM-T4 [42], HSB-2 [43], Jurkat (clone E6.1) [44], Molt4 [45], PM1 [46] and SupT1 [47] were also used. A2.01, CEM-T4, C8166-45, C91-PL, HSB-2, Molt-4, MT2 and PM1 were provided by the NIH AIDS Repository Reagent Program (Germantown, MD), while MJ and Jurkat E6.1 cells were provided by the American Type Culture Collec- 
tion (ATCC) (Manassas, CA) and the S1T cell line was obtained from Dr. D. Branch (University of Toronto, Toronto, Canada). The 293T cell line [48] derives from human embryonic kidney cells and was obtained from the ATCC. PBMCs were isolated from healthy donors using Ficoll-Hypaque density gradient centrifugation. PBMCs were stimulated for $72 \mathrm{~h}$ with PHA-L $(1 \mu \mathrm{g} / \mathrm{ml})$ (Sigma-Aldrich, Oakville, Canada) and IL-2 (30 U/ml) and subsequently maintained in the presence of IL-2. All cell lines were maintained in complete medium (RPMI1640 or DMEM) supplemented with $10 \%$ foetal bovine serum (Wisent, St-Jean-Baptiste de Rouville, Canada), Lglutamine $(2 \mathrm{mM})$, penicillin $(100 \mathrm{U} / \mathrm{ml})$ and streptomycin $(100 \mu \mathrm{g} / \mathrm{ml})$ (Wisent, St-Jean-Baptiste de Rouville, Canada). The following reagent was obtained through the AIDS Research and Reference Reagent Program, Division AIDS, NIAID, NIH: Human rIL-2 from Dr. Maurice Gately, Hoffmann-La Roche Inc [49].

\section{Plasmids}

Expression vectors for wild-type and mutant Tax proteins (i.e. Tax 703, Tax $\Delta 3$ and Tax M22) were obtained from Dr. K. Matsumoto (Osaka Red Cross Blood Center, Osaka, Japan) and cloned into ph $\beta$ Pr.1neo under the control of the $\beta$-actin promoter [50]. The K30 proviral DNA was obtained from the NIH AIDS Repository Reagent Program. The pHTLV-Luc vector (kindly provided by Dr. W.C. Greene, University of California of San Francisco; San Francisco, CA) contains the luciferase gene under the control of HTLV-I LTR. The pNF-кB-Luc and pSRE-Luc luciferase expression vectors were purchased from Clontech (Mountain View CA). The pNL4.3Luc+Env-Vpr+ vector (kindly provided by Dr. N.R. Landau; The Salk Institute for Biological Studies, La Jolla, CA) encodes a complete HIV-1 genome in which the envelope gene has been inactivated and the luciferase gene inserted in the region coding for the Nef viral protein. The pSV HTLV-I env vector (kindly provided by Dr. R. Sutton, Baylor College of Medicine, Houston, TX) harbours the HTLV-I gp46 cDNA under the control of the SV40 promoter. The pActin-LacZ vector contains the $\beta$-galactosidase gene under the control of the actin promoter. The pLTRX-Luc construct was kindly provided by O. Schwartz (Unité d'oncologie virale, Institut Pasteur, Paris, France) and contains the HIV-1 LTR from the HIV-1 LAI strain positioned upstream of the luciferase reporter gene [51].

\section{Construction of the human galectin-I promoter vector}

A PCR-based approach was used to insert the luciferase gene under the control of the galectin-1 promoter. Genomic DNA was isolated from 293T cells with the QIAamp DNA Blood Mini Kit (QIAGEN, Mississauga, Canada). Two fragments of the galectin-1 promoter region $(0.5 \mathrm{~kb}$ or $1.2 \mathrm{~kb})$ were amplified from $200 \mathrm{ng}$ of genomic DNA by PCR with the forward primers gal- $0.5 \mathrm{~kb}$
(5'-GTTAAGTCAGTGGCCCTCTGCAG-3') or gal-1.2 kb (5'-CAGAGGAGATGTTAAGAGAGCAGAC-3') and the reverse primer gal-as1 (5'-CGCACCAGCTGTCAGAAGACTCC-3'). PCR amplifications were then performed in the presence of $0.2 \mathrm{mM}$ dNTPs, $1 \mu \mathrm{M}$ of each primer, $1 \mathrm{U}$ of Vent polymerase (New England Biolab, Pickering, Canada) through 35 cycles (denaturing at $95^{\circ} \mathrm{C}$ for $1 \mathrm{~min}$, annealing at $63^{\circ} \mathrm{C}$ for $1 \mathrm{~min}$ and polymerizing at $72^{\circ} \mathrm{C}$ for $1 \mathrm{~min})$. The PCR products were purified with the QIAquick PCR purification kit (Qiagen, Mississauga, Canada) and ligated into the pBluescript SK (pBSK) vector in SmaI. Positive clones were sequenced and compared to the human galectin-1 promoter sequence (Genbank Accession no [ㄹ83844.5]). The $0.5 \mathrm{~kb}$ and $1.2 \mathrm{~kb}$ galectin1 promoter fragments were cut out of pBSK with SacI and NdeI enzymes and ligated into pGL3-Basic (Promega; Neapean, Canada) digested by SacI and SmaI.

\section{Preparation of galectin-I}

Recombinant human galectin-1 was purified as previously described [35]. Purified galectin-1 was passed through Detoxi-gel endotoxin-removing gels (Pierce; Rockford, IL). The activity of galectin-1 to bind to glycan and to cross-link neighbouring cells was weekly tested by performing a hemagglutination assay with concentrations ranging from 1 to $4 \mu \mathrm{M}$.

\section{RT-PCR}

Total RNA from A2.01, HSB-2, Jurkat (clone E6.1), Molt4, CEM-T4, PM1, Sup T1, C8166-45, C91-PL, MJ, MT2 and S1T cell lines or from transfected 293T cells was extracted with the TRIzol reagent (Invitrogen; Burlington, Canada). Extracted RNA (5 $\mu \mathrm{g})$ was then reverse transcripted with the M-MLV reverse transcriptase (1 U) (Invitrogen; Burlington, Canada) and oligo dT primers. Next, PCR amplification was performed on the resulting CDNA with primers act-s (5'-CGTGACATTAAGGAGAAGCTGTGC-3') and act-as (5'-TCTAGGAGGAGCAATGATCTTGAT-3') for $\beta$-actin mRNA; gal-s (5'GACTCAATCATGGCTTGTGGTCTG-3') and gal-as (5'GCTGATTTCAGTCAAAGGCCACAC-3') for galectin-1 mRNA; or tax-s (5'-ATGGCCCACTTCCCAGGGTTTGGAC-3') and tax-as (5'-TCAGACTTCTGTTTCGAGGAAATG-3') for Tax mRNA. PCR amplifications were performed in the presence of $0.2 \mathrm{mM}$ dNTPs, $1 \mu \mathrm{M}$ of each primer, $1 \mathrm{U}$ Vent polymerase and 30 amplification cycles (denaturation at $95^{\circ} \mathrm{C}$ for $1 \mathrm{~min}$, annealing at $55^{\circ} \mathrm{C}$ for galectin, $58^{\circ} \mathrm{C}$ for $\beta$-actin and $65^{\circ} \mathrm{C}$ for Tax for $1 \mathrm{~min}$ and polymerization at $72^{\circ} \mathrm{C}$ for $1 \mathrm{~min}$ ). The PCR products were then migrated on a $1.5 \%$ agarose gel.

\section{Real-time RT-PCR}

RNA was first isolated from 293T transfected cells, by the RNeasy ${ }^{\circledast}$ Plus mini Kit (Qiagen, Mississauga, ON, Canada) according to the manufacturer's instructions. Real-time 
RT-PCR reactions were then performed in the presence of each specific primer. Briefly, RNA $(5 \mu \mathrm{g})$ was reverse transcripted with the M-MLV reverse transcriptase (1 U) (Invitrogen) and oligo dT primers. PCR reactions were then initiated in a final volume of $10 \mu \mathrm{l}$ containing $1 \mu \mathrm{l}$ of cDNA, $0.5 \mu \mathrm{M}$ of each primer, and $1 \times$ reaction mix, including Taq DNA polymerase, the reaction buffer, and SYBR green $\left(\right.$ SYBR $^{\oplus}$ Premix Ex Taq ${ }^{\mathrm{TM}}$ Perfect Real Time, Fisher Scientific Canada, Montréal, Canada). All primer sequences were generated using the Light Cycler Probe Design Software 2.0 (Roche, Basel, Switzerland) and checked for specificity using GenBank Blast analysis. The galectin-1 primers were the following: 5'-GACTCAATCATGGCTTGTGGTCTG-3' (reverse) and 5'-GCTGATTTCAGTCAAAGGCCACAC-3' (forward). In all PCR reactions, negative controls consisting of a RT-like reaction step with no added reverse transcriptase in addition to a blank sample were carried out and showed no PCR amplification (data not shown). Thermal cycling for quantification of both transcripts was initiated with a denaturation step of $95^{\circ} \mathrm{C}$ for 10 seconds, followed by 50 cycles (denaturation at $94^{\circ} \mathrm{C}$ for 3 seconds, $57^{\circ} \mathrm{C}$ for annealing during $15 \mathrm{sec}-$ onds, and elongation at $72^{\circ} \mathrm{C}$ for 12 seconds). Amplification of the human HPRT-1 (Hypoxanthine Phosphoribosyl Transferase 1) cDNA with forward and reverse primers (5'-AAGCTTGCGACCTTGACC-3' and 5'GACCAGTCAACAGGGGACATAA-3', respectively) was used as a reference gene for normalisation. To verify the amplification of each single product with its suitable melting temperature, and to provide an accurate quantification with the Rel Quant Software, dissociation curves were run for all reactions and amplified products were visualized by electrophoresis on a $1.5 \%$ agarose gel.

\section{Transient transfections}

Jurkat, CEM-T4 and SupT1 cells $\left(1 \times 10^{7}\right)$ were transiently transfected by electroporation as previously described [52]. Briefly, cells were electroporated with 15-20 $\mu \mathrm{g}$ of DNA in complete medium containing $10 \mu \mathrm{g} / \mathrm{ml}$ DEAEDEXTRAN in a $0.4 \mathrm{~cm}$ electroporation cuvette with the Bio-Rad Gene Pulser II system $(250 \mathrm{~V}, 950 \mu \mathrm{F})$. In transfection experiments assessing NF- $\mathrm{BB}$ activation, 24 hours after transfection, cells were either untreated or treated with PMA $(20 \mathrm{ng} / \mathrm{ml})$ or TNF- $\alpha(10 \mathrm{ng} / \mathrm{ml})$ (SigmaAldrich, St-Louis MO) for a period of 8 hours. For the Sup $\mathrm{T} 1$ cell line, DMSO was also added at a final concentration of $1.25 \%$. For certain experiments, extracted RNA were analysed by RT-PCR, while luciferase activity was evaluated in other transfection experiments as previously described [53]. In these latter experiments, $\beta$-galactosidase activity was also measured through the GalactoLight $^{\mathrm{TM}}$ commercial kit (Applied Biosystems, Bedford, MA) according to the manufacturer's protocol. Experiments were conducted in triplicates and both luciferase and $\beta$ galactosidase activities are represented as the average value +/- standard deviation. Transfection of 293 T cells with the various Tax expression vectors $(40 \mu \mathrm{g})$ were performed as previously described [54].

\section{Quantification of extracellular galectin-I levels}

A2.01, HSB-2, Jurkat (clone E6.1), Molt-4, PM1, CEM-T4, SupT1, C8166-45, C91-PL, MJ, MT2 and S1T cell lines were seeded at $5 \times 10^{5} \mathrm{cells} / \mathrm{ml}$, and incubated for 48 hours. The supernatants were passed through a $0.22 \mu \mathrm{m}$ filter, and lysed with a $5 \times$ disruption buffer (PBS $1 \times$, $0.05 \%$ Tween-20, 2.5\% Triton X-100 and 1\% Trypan blue). Galectin-1 concentration was determined by an in house ELISA assay specific for galectin-1.

\section{Virus production and infection assay}

HIV-1-based viruses pseudotyped with the HTLV-I envelope protein were prepared as previously described [54]. Briefly, 293T cells were cotransfected with $13 \mu \mathrm{g}$ of the envelope-defective luciferase-expressing HIV-1 proviral clone pNL4.3L+E-Vpr+ and $26 \mu \mathrm{g}$ of pSV HTLV-I env by calcium phosphate coprecipitation. The cells were washed with PBS $1 \times 16$ hours after transfection and incubated another 24 hours. Supernatants were then filtered through a $0.22 \mu \mathrm{m}$-pore-size filter to remove cells and cellular debris. Viral preparations were stored at $-85^{\circ} \mathrm{C}$ until needed. Virus particles were titrated through the use of a sandwich ELISA specific for the HIV-1 p24 capsid protein [55]. Pseudotyped virions were subsequently used in infection experiments of Jurkat and PBMCs. Cells were initially incubated with various concentrations of galectin-1 (ranging from 0 to $4 \mu \mathrm{M}$ ) for 30 minutes in the absence or presence of $50 \mathrm{mM}$ lactose and then infected with luciferase-encoding HTLV-I env-pseudotyped viruses (10 ng of p24 per $1 \times 10^{5}$ cells) for 48 hours at $37^{\circ} \mathrm{C}$ before lysis. In certain experiments, 24 hours after transfection, TNF- $\alpha$ was added at a concentration of $10 \mathrm{ng} / \mathrm{ml}$. Luciferase activity was next measured as previously described [53]. Experiments were conducted in triplicates and luciferase activity represents the average value +/standard deviation.

\section{Co-culture assays}

Jurkat cells were transfected with pHTLV-Luc by electroporation as described above. HTLV-I-infected C91-PL cells (1 $\times 10^{5}$ ) were then added to an equal number of transfected Jurkat cells in a flat-bottom 96-well plate. Galectin-1 was added in various concentrations (ranging from 0 to $4 \mu \mathrm{M}$ ) in the absence or presence of $50 \mathrm{mM}$ lactose for 24 hours at $37^{\circ} \mathrm{C}$ before lysis and quantification of luciferase activity. As a control, transfected cells were similarly incubated with supernatant of C91-PL cells harvested after a 24 hour incubation at a concentration of $1 \times 10^{6}$ cells $/ \mathrm{ml}$ and filtered through a $0.22 \mu \mathrm{M}$ filter. Values are expressed as the average luciferase activity $+/$ - standard deviation calculated from triplicates. 


\section{Statistical analyses}

Statistical analyses were carried out according to the methods outlined in Zar (1984) [56]. Homoscedasticity were determined using $\mathrm{F}_{\max }$. When homoscedasticity assumptions were met, means were compared using Student's $t$ test, or a single factor ANOVA followed by Dunnett's multiple comparisons when more that two means were considered. When homoscedasticity assumptions were not met, means were compared using a Kruskal-Wallis single factor ANOVA followed by Dunnett's multiple comparisons when more than two means were considered. $P$ values of less than 0.05 were deemed statistically significant, whereas $p$ values lower than 0.01 were considered highly significant. Computations were carried out using GraphPad PRISM version 3.03 statistical software.

\section{Results \\ Galectin-I is more strongly expressed in HTLV-I-infected T cells than in non-infected $T$ cells}

Previous studies have suggested that expression of various genes are positively modulated in HTLV-I-infected cells $[19,57]$. In order to determine whether galectin-1 expression is indeed altered in HTLV-I-infected cells, RT-PCR experiments were performed to compare the level of galectin-1 gene expression between non infected human $\mathrm{T}$ cells and HTLV-I-infected human T cells. Sequence-specific primers were derived from two different exons to insure that amplified products were derived from cDNA and not contaminating genomic DNA. As presented in Figure 1, results showed that galectin-1 was expressed in all HTLV-I-infected cell lines studied in contrast to noninfected T cell lines in which galectin-1 mRNA expression was either undetectable or slightly expressed. These results hence suggested a possible association between HTLV-I infection of T cells and increased expression of galectin- 1 .

\section{Tax induces galectin-I expression}

As some of the tested HTLV-I-infected cells have been reported to only express the viral Tax protein, we then looked if Tax expression indeed could modulate galectin mRNA levels. 293T cells were transfected with either a vector containing a complete HTLV-I proviral genome (i.e. K30), or expression vectors coding for Tax WT or Tax mutants defective in their ability to activate transcription factors NF- $\mathrm{B}$, SRF and/or CREB. Galectin-1 expression was then analyzed by RT-PCR. As shown in Figure 2A, transfection of the K30 proviral DNA led to an induction in the expression of galectin-1. In addition, comparable induced levels of galectin-1 mRNA were observed in 293T cells expressing wild-type Tax and both Tax mutants defective for CREB and SRF activation (Tax 703 and Tax $\triangle 3$ ). In contrast, cells that were transfected with the Tax M22 (deficient in NF- $\kappa \mathrm{B}$ activation) expression vector did not demonstrate a significant difference in galectin-1 mRNA levels when compared to cells transfected with the control vector (Figure 2A). As RT-PCR experiments further show that cells expressed similar levels of Tax, this difference in upregulation of galectin-1 mRNA level was not due to differences in the expression level of the different Tax proteins in transfected $293 \mathrm{~T}$ cells. In order to confirm these results, RNA from 293T cells transfected with the various Tax expression vectors were quantitatively analysed for galectin-1 expression by real-time RT-PCR. Results presented in Figure 2B again revealed an important decrease in Tax M22-mediated activation of galectin-1 expression while other Tax mutants demonstrated a comparable upregulation to the one measured with wild-type Tax.

Next, RT-PCR analyses were performed in a more representative context, i.e T cell lines. Hence, the wild-type Tax expression vector was transfected in CEM-T4 and SupT1 T cell lines and analysed by RT-PCR for galectin-1 expression. As denoted in Figure 2C, Tax expression indeed increased the expression of galectin-1 in both $\mathrm{T}$ cell lines.

As the data suggest that HTLV-I Tax induces the expression of galectin-1 in non-T and T cell lines, it is likely that Tax plays a role in the modulation of galectin-1 mRNA levels in HTLV-I-infected cell lines.

\section{Tax induces transcription from the galectin-I promoter}

To determine whether the effect of Tax on galectin-1 expression resulted from direct activation of transcription from the galectin-1 promoter, two different luciferase-encoding vectors driven by the human galectin-1 promoter were constructed. Two fragments of $0.5 \mathrm{kbp}$ and $1.2 \mathrm{kbp}$ containing the transcription initiation site deduced from sequence homology with the mouse galectin-1 gene were derived from the human galectin-1 promoter region. Both fragments were cloned upstream of the luciferase reporter gene of the pGL3Basic vector. Before determining the effect of Tax on these constructs, the Tax M22 expression vector was first tested in the context of Jurkat cells to see if it was specifically deficient in activating NF- $\kappa \mathrm{B}$ (Figure $3 \mathrm{~A}$ ). These results indeed confirmed previous studies in Jurkat cells: Tax M22 was only defective in activating NF- $\mathrm{B}$ unlike Tax 703, which was comparable to wild-type Tax for NF- $\kappa \mathrm{B}$ activation but greatly affected in its capacity to activate both SRF and CREB (the latter being tested with the HTLV-I LTR-driven reporter construct mainly responsive to CREB activation). As Tax M22 was behaving as expected in the Jurkat $\mathrm{T}$ cell line, the two galectin-1 promoter constructs were next cotransfected with Tax WT or Tax M22 expression vectors along with pActinLacZ into CEM-T4, Jurkat E6.1 and SupT1 T cell lines and promoter activity was then evaluated by luciferase activity after normalisation (Figure 3B, C). When compared to cells transfected with the control vector, the $0.5 \mathrm{~kb}$ galectin- 1 promoter construct demonstrated an increase of 10- to 15-fold following expression of Tax WT while Tax M22 expression led to a modest 2 to 4 -fold induction (Figure 3B). For the 1.2 


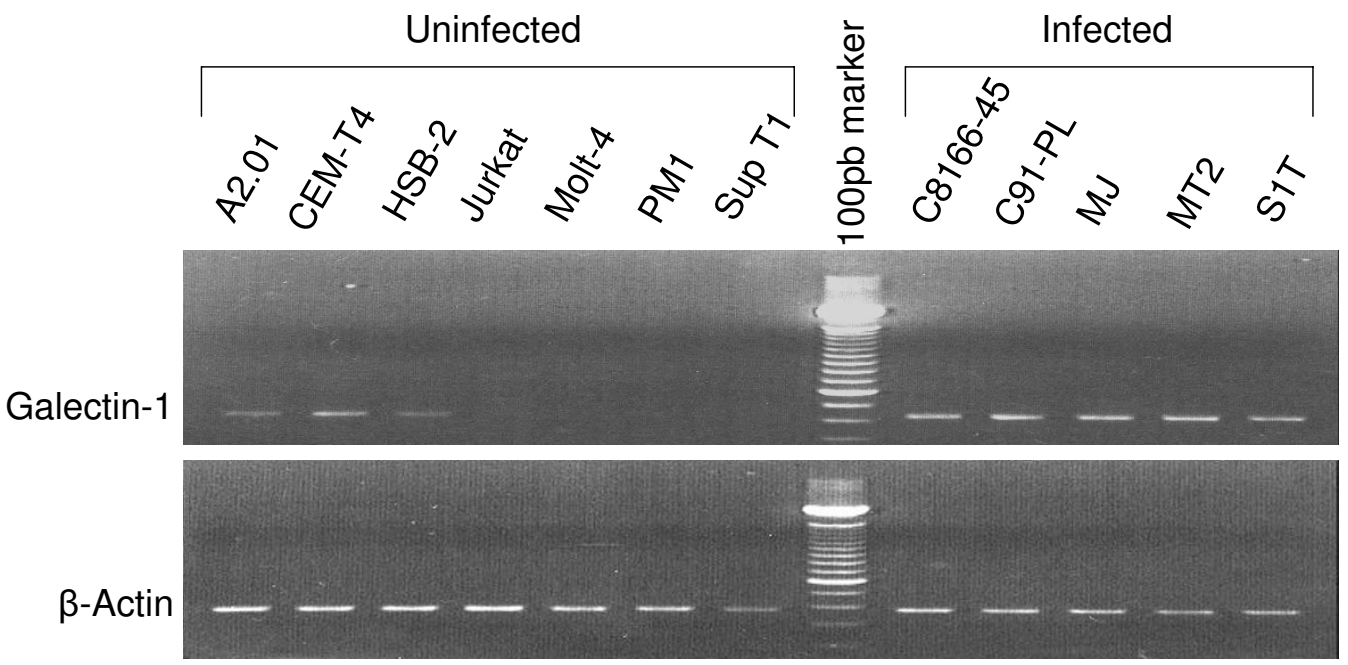

\section{Figure I}

Comparative analysis of galectin-I expression in different uninfected $T$ cell lines and HTLV-I chronicallyinfected cell lines. Galectin-I mRNA levels were measured by RT-PCR analyses on total RNA isolated from non-infected (A2.0I, CEM-T4, HSB-2, JurkatE6.I, Molt-4, PMI, and Sup TI) and chronically HTLV-I-infected cells (C8I66-45, C9I-PL, MJ, MT2 and SIT). PCR products were separated by electrophoresis on I.5\% agarose gels. Expression of $\beta$-actin mRNA served as an internal control for normalization.

kb galectin-1 promoter construct, expression of TaxWT led to a 10- to 35-fold increase in promoter activity compared to 2 to 6 fold activation when the TaxM22 expression vector was transfected (Figure 3C). These results suggested that the viral protein Tax upregulates transcription from the galectin-1 promoter region, which likely accounts for the observed increase in galectin-1 mRNA levels in both HTLV-I-infected cells and cells transfected with the Tax expression vector.

Lower induction of the galectin-1 promoter by TaxM22, which is deficient for NF- $\kappa \mathrm{B}$ activation, raised the possibility that this transcription factor was crucial for Taxmediated increase in galectin-1 expression. However, Jurkat cells transfected with the $1.2 \mathrm{~kb}$ galectin-1 promoter construct did not show higher luciferase activity upon stimulation with two known potent NF- $\mathrm{KB}$ activating agents, PMA and TNF- $\alpha$, thereby strongly suggesting that NF- $\mathrm{BB}$ was not involved in the modulation of galectin-1 promoter activity by Tax (Figure 3D). As no known NF$\kappa \mathrm{B}$-binding sites have been identified from galectin-1 promoter sequence analyses, these results strongly hint on the involvement of a Tax-activated transcription factor different from NF-kB in galectin-1 expression.

Galectin-I is more abundant in the supernatant of HTLV-I chronically infected $T$ cell lines than in the supernatant of non-infected cells

As we have demonstrated that HTLV-I-infected cell lines express higher levels of galectin-1 mRNA, we next studied whether these cells produced more extracellular galectin-
1. Figure 4 indeed shows that HTLV-I-infected T cell lines released 13 to 50 times higher levels of extracellular galectin-1 than the average level produced by uninfected T cell lines. Interestingly, the S1T T cell line demonstrated the lowest level of extracellular galectin-1 and is known to poorly express Tax.

Together, the data suggest that mRNA and secretion of galectin-1 were both upregulated in cells chronically infected with HTLV-I.

Galectin-I increases the infectivity of pseudotyped viruses As galectin-1 can stabilize cell-to-cell and cell-virus interactions by cross-linking different entities, we studied whether extracellular galectin-1 could facilitate HTLV-I infection. To initiate this study, Jurkat E6.1 cells were first infected with luciferase-expressing HIV virions pseudotyped with the HTLV-I gp46 envelope in the presence of various concentrations of purified galectin- $1(0-4 \mu \mathrm{M})$ for 48 hours; luciferase activity was then measured. The use of HTLV-I gp46-pseudotyped virions that can express luciferase allows us to detect a single round of infection and although different from wild-type HTLV-I virions, it should be representative of the type of interactions and fusogenic activities of gp 46 occurring on the surface of HTLV-I virions upon infection. Infection of Jurkat E6.1 cells by the pseudotyped virions was increased by 1.6 fold in the presence of $2 \mu \mathrm{M}$ of galectin- 1 , an increase which was statistically significant $(\mathrm{F}=6.764, \mathrm{p}=0.0138)$ (Figure $5 \mathrm{~A})$. Lactose, an inhibitor of galectin-1, inhibited this 

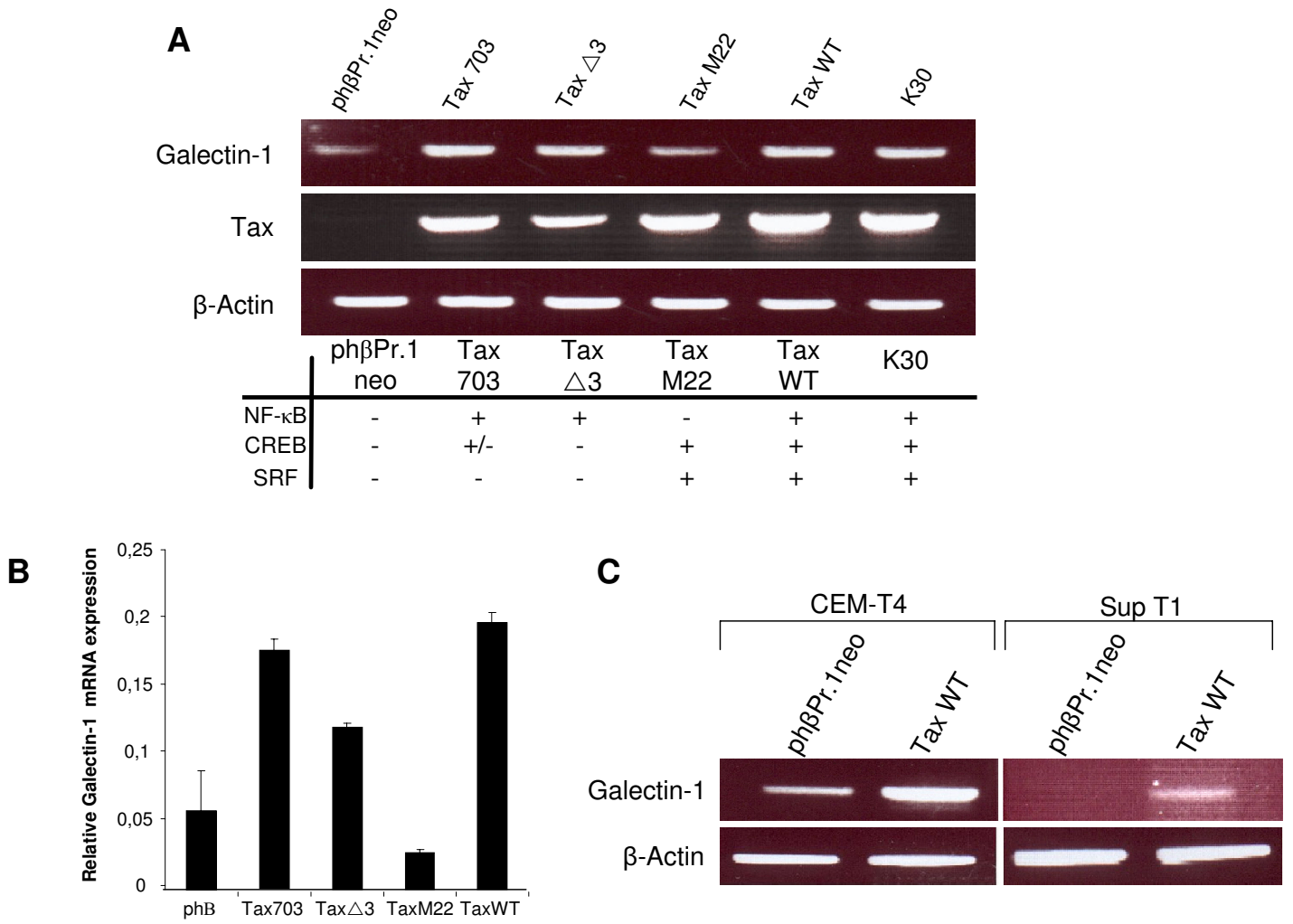

\section{Figure 2}

Analysis of galectin-I expression in WT and mutant Tax-expressing cells. A,B. 293T cells were transfected with 40 $\mu \mathrm{g}$ of the control vector ph $\beta \mathrm{Pr}$. Ineo, Tax expression vectors (Tax 703, Tax $\Delta 3$, Tax M22, and Tax WT) or full-length proviral DNA K30 clone. RT-PCR analyses for galectin-I, Tax and $\beta$-actin RNA levels (A) and real-time RT-PCR for galectin-I RNA levels (B) were conducted on RNA from each transfected conditions. The activated transcription factors for each Tax expression vectors are indicated below panel A. C. CEM-T4 and Sup TI cell lines were transfected with $20 \mu \mathrm{g}$ of the control vector $\mathrm{pH} \beta$ Pr.Ineo or Tax WT expression vector. Total RNA was analyzed by RT-PCR for galectin-I and $\beta$-actin RNA levels. PCR products were separated by electrophoresis on $1.5 \%$ agarose gels.

galectin-1-promoting effect on HTLV-I infectivity, suggesting that the carbohydrate binding activity of this protein is involved in this increase. In order to increase the luciferase signal, infection of Jurkat cells were also conducted in the presence of the LTR activating agent TNF- $\alpha$. Results depicted in Figure 5B again demonstrated a highly significant $(t=5, p=0.0069)$ positive effect of galectin-1 on infectivity of gp46-pseudotyped virions.

A more physiological model was also used to study the impact of soluble galectin-1 on infection by HTLV-I pseudotyped virus. PBMCs isolated from a healthy donor were stimulated with IL-2 and PHA-L for 72 hours and, after washing, were then similarly treated upon infection by the HTLV-I gp46-pseudotyped virions. The infection of
PBMCs by pseudotyped virions was increased by 1.8 fold in the presence of $4 \mu \mathrm{M}$ of galectin- 1 (Figure $5 \mathrm{C}$ ). The positive modulation on virus infection was determined to be statistically significant $(\mathrm{F}=4.364, \mathrm{p}=0.0425)$.

To eliminate the possibility that galectin-1 was positively modulating LTR activity of the integrated proviral DNA of our gp46-pseudotyped virions, Jurkat cells were transfected with a vector containing the luciferase reporter gene under the control of the HIV-1 LTR, after which different concentrations of galectin-1 $(0-4 \mu \mathrm{M})$ was added. Measurement of luciferase activity demonstrated that the presence of galectin-1 had no impact on the transcription levels dependent on the HIV-1 LTR (data not shown). 

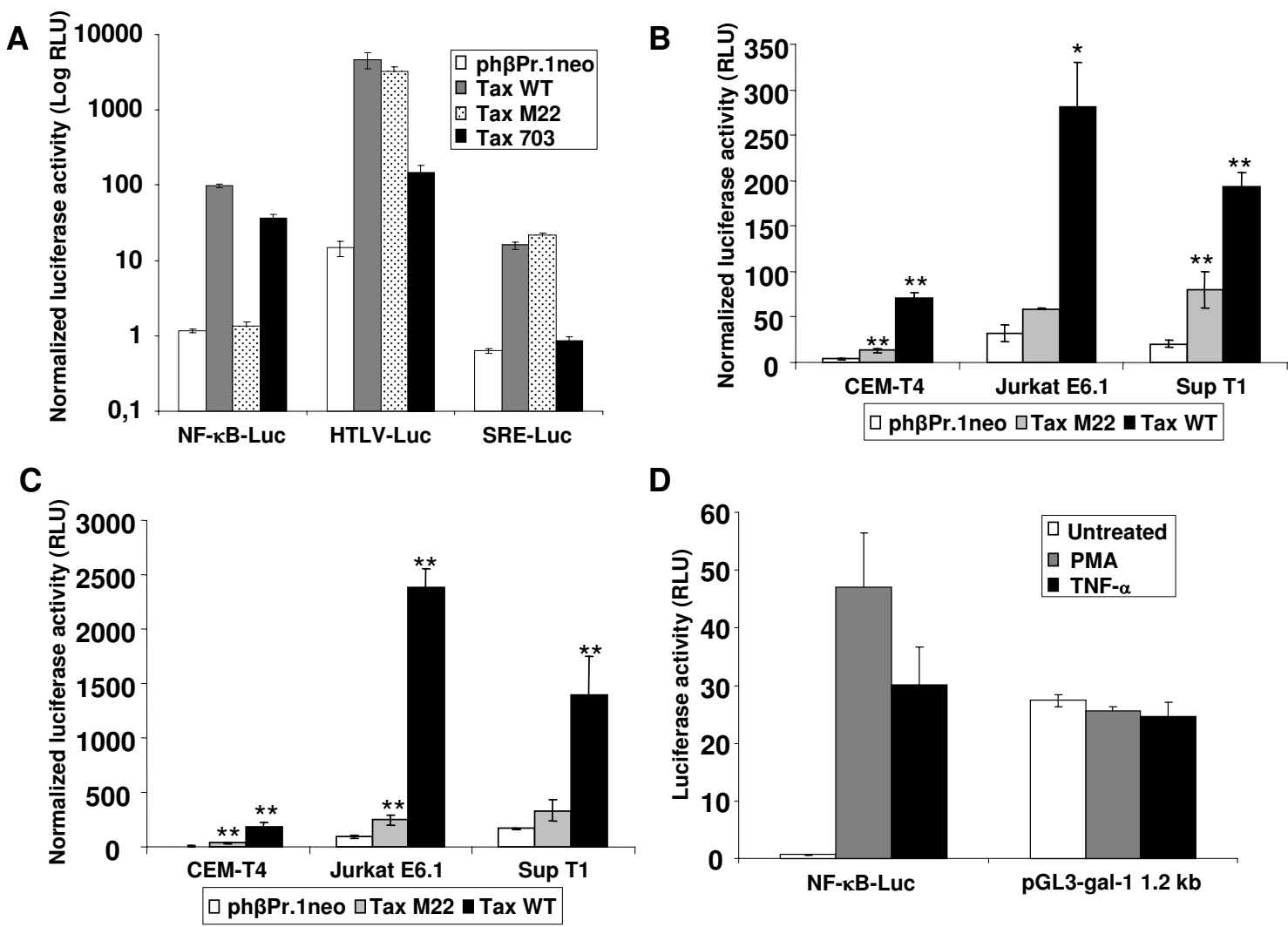

\section{Figure 3}

Activation of the galectin- I promoter by Tax expression in transfected $\mathbf{T}$ cell lines. A. Jurkat cells were transfected with either pNF-kB-Luc, PHTLV-Luc or pSRE-Luc $(7.5 \mu \mathrm{g})$ along with $\mathrm{pH} \beta$ Pr. Ineo (control vector) or expression vectors for Tax WT, Tax M22 or Tax $703(7.5 \mu \mathrm{g})$ and pActin-LacZ $(5 \mu \mathrm{g})$. B,C. Jurkat, CEM-T4 and Sup TI T cell lines were co-transfected with $\mathrm{pH} \beta \mathrm{Pr}$. Ineo (control vector) or expression vectors for Tax WT or Tax M22 (7.5 $\mu$ g), the galectin-I promoter reporter constructs pGL3-gal-I $0.5 \mathrm{~kb}(\mathbf{B})$ or pGL3-gal-I I.2 kb (C) $(7.5 \mu \mathrm{g})$ and pActin-LacZ (5 $\mu \mathrm{g})$. D. Jurkat cells were transfected with pNF- $\kappa B$-Luc or pGL3-gal-I I.2 kb (I5 $\mu \mathrm{g})$. After transfection (24 hours), cells were either left untreated or stimulated with PMA or TNF- $\alpha$ for 8 hours. Luciferase and $\beta$-galactosidase activities were determined 48 hours after transfection as described in Materials and Methods. In panels A, B and $\mathbf{C}$, luciferase activity was normalized on the basis of the $\beta$-galactosidase activity. The results represent the mean of three independent transfections $+/-$ standard deviations $\left({ }^{*} \mathrm{p}<0.05\right.$; $*^{*} \mathrm{p}<$ $0.01)$.

Hence, these results show that extracellular galectin-1 increases infection of a $\mathrm{T}$ cell line and PBMCs by free HTLV-I gp46-pseudotyped viruses and that this increase relies on the binding of cell/virus surface carbohydrates by the galectin-1 CRD.

\section{Effect of galectin-I on gp46-mediated cell fusion in a co- culture assay}

To study whether galectin-1 can possibly facilitate cell fusion events, a co-culture system allowing a quantitative evaluation of cell fusion by luciferase assay was used [58]. This cell line model provided another useful system to assess the gp46-mediated fusion and was thus used to further confirm the results obtained with the gp46-pseudotyped virions. Our results had previously strongly suggested that this induction of luciferase activity could not be attributed to HTLV-I infection following cell-to-cell contact, but was rather involving cytoplasmic exchange likely mediated by the fusogenic capacity of gp46. Briefly, Jurkat E6.1 cells were transfected with pHTLV-Luc containing the HTLV-I LTR upstream of the luciferase gene and were subsequently co-cultured with the HTLV-Iinfected cell line, C91-PL. Cytoplasmic exchange can then be estimated by assessing luciferase activity as Tax present 


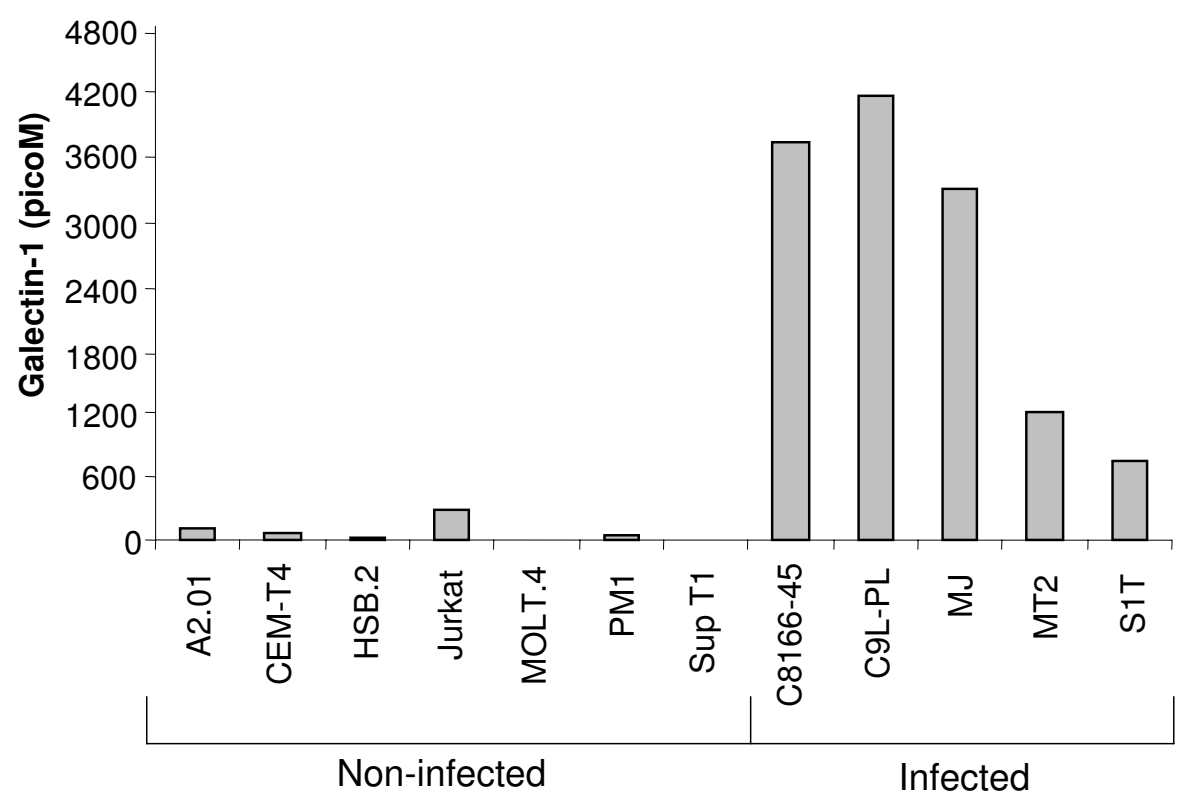

\section{Figure 4}

Comparative analysis of extracellular galectin-I levels between uninfected and chronically HTLV-I-infected cell lines. A2.0I, CEM-T4, HSB-2, Jurkat E6.I, Molt-4, PMI, Sup TI, C8I66-45, C9I-PL, MJ, MT2 and SIT cell lines were cultured for 48 hours starting at a concentration of $5 \times 10^{5}$ cells $/ \mathrm{ml}$. The supernatants were then collected, passed through a 0.22 $\mu \mathrm{m}$ filter and analysed for galectin-I secretion by a galectin-I-specific ELISA as described in Materials and Methods.

in infected C91-PL cells should, upon cellular fusion, activate HTLV-I LTR activity in transfected Jurkat cells. This assay was thus tested in the presence of different amounts of galectin-1 (0-4 $\mu \mathrm{M})$ for 24 hours, after which luciferase activity was measured. A dose-dependent (and statistically significant at $4 \mu \mathrm{M} ; \mathrm{F}=4.192, \mathrm{p}=0.0466$ ) increase in luciferase activity mediated by galectin-1 was noted (Figure 6A). Again, this induction was lactose-sensitive. Of note, a small but non-significant effect of lactose was apparent in co-cultured cells which were not treated with galectin1 , suggesting a possible impact of endogenous galectin-1 in cell fusion affecting luciferase activity. As a control, supernatant from C91-PL cells incubated in the presence of transfected Jurkat cells did not lead to any significant increase in luciferase activity either in the absence or presence of galectin-1, thereby ruling out the effect of extracellular factors acting on HTLV-I LTR activity (Figure 6B). In addition, although we cannot rule out a contribution in this signal from infection events by HTLV-I particles on Jurkat cells, which would similarly induce luciferase expression, previous experiments have suggested that the first 24-hour time course preferentially involves HTLV-Idriven syncytium formation in the modulation of luciferase assay [58].

These results show that soluble galectin-1 can also increase cytoplasmic cell exchange likely occurring though gp46-dependent cell fusion events between an HTLV-I-infected cells and uninfected T cells, again being inhibited by the addition of lactose.

\section{Discussion}

HTLV-I is a poorly infectious virus and, in this regard, the presence of various molecules that facilitate infection may 
A

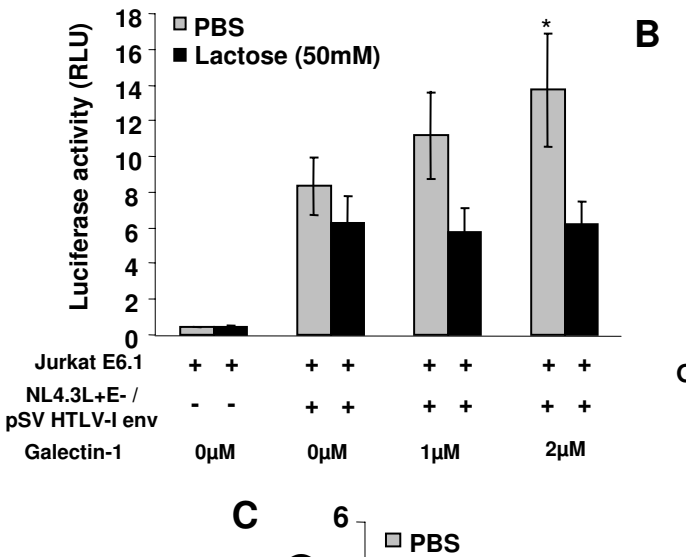

B

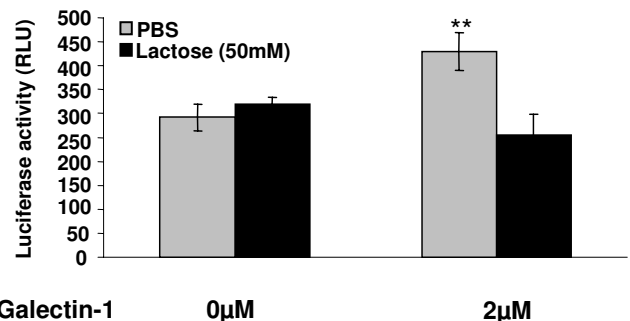

Galectin-1 $2 \mu \mathrm{M}$

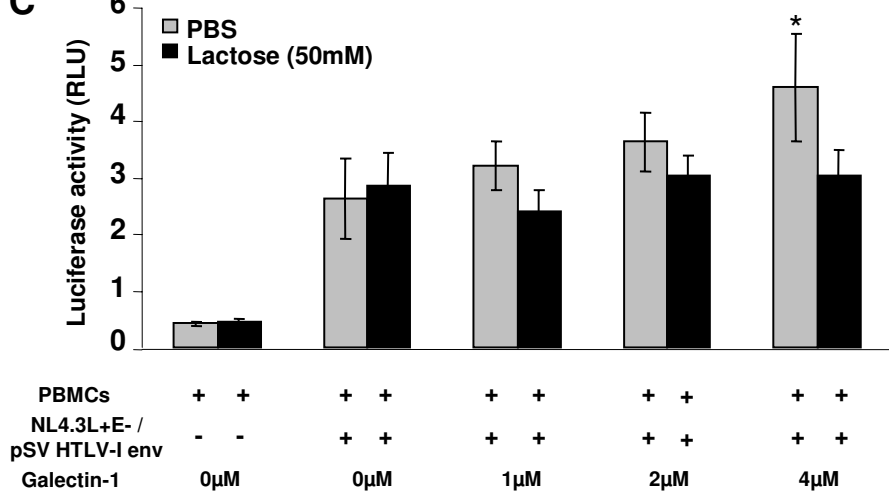

\section{Figure 5}

Soluble galectin-I positively impacts on the infection of T cell line and PBMCs by HTLV-I-envelope-pseudotyped viruses. Jurkat cells $(\mathbf{A}, \mathbf{B})$ or PBMCs $(\mathbf{C})\left(\mathrm{I} \times 10^{5}\right.$ cells) were infected with $10 \mathrm{ng}(\mathrm{p} 24)$ of HTLV-I envelope-pseudotyped HIV-I viruses in the presence of different concentrations of purified galectin-I $(0-4 \mu \mathrm{M})$, with or without lactose (50 $\mathrm{mM})$. B, Jurkat cells were also treated with TNF- $\alpha(10 \mathrm{ng} / \mathrm{ml})$. Luciferase activities were measured 48 hours post-infection. The results represent three independent infections and are expressed as the mean luciferase activity value $+/-$ standard deviation $\left(*^{*}<0.05\right.$; ** $p<0.0$ I).

be important for viral transmission. Several studies have been conducted on the implication of adhesion molecules incorporated by retroviruses (especially for HIV-1) and their positive impact on viral replication [59]. Similar studies have revealed that cell surface adhesion molecules could affect the infection and syncytium formation related to HTLV-I $[8,13,60-63]$. In addition, certain studies have also indicated that soluble factors were also possible modulators of the HTLV-I infection process $[64,65]$. Galectins are a family of proteins involved in cell adhesion but few studies have been conducted on their possible involvement in viral infection [66]. In the present study, we have focused on galectin-1, mainly because of its capacity to mediate cell-to-cell contact but also because this protein is expressed by activated T cells and cells from lymphoid tissue, a major site of infection by HTLV-I.

In this study, we have demonstrated that galectin- 1 is more strongly expressed and secreted in chronically HTLV-I-infected T cell lines compared to uninfected T cells. These results agree with the study of Pise-Masison and colleagues, which showed through DNA microarray experiments that galectin-1 gene expression is upregulated in HTLV-I-transformed and immortalized cell lines [19]. Furthermore, we have demonstrated that the viral Tax protein could be involved in the upregulation of galectin-1 expression. Generally, Tax directly activates gene transcription by the activation of CREB, NF- $\mathrm{KB}$ and/or SRF transcription factor [67]. Using Tax mutants and known 
A

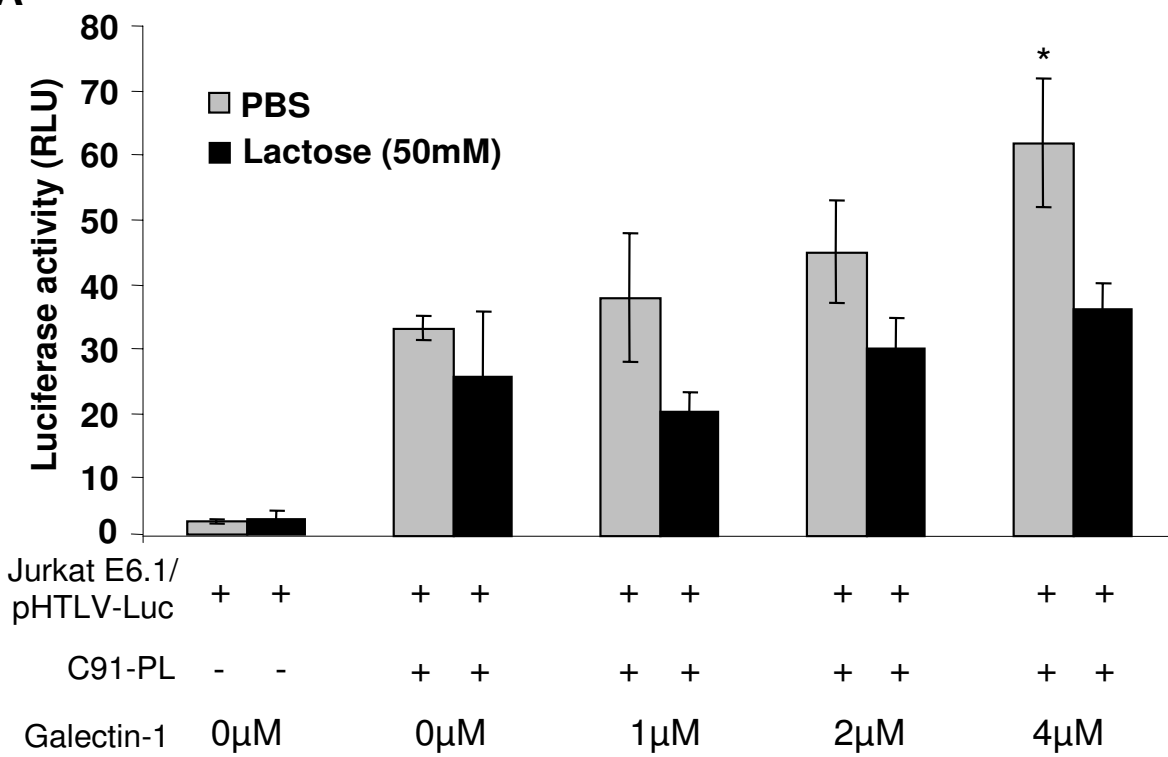

B
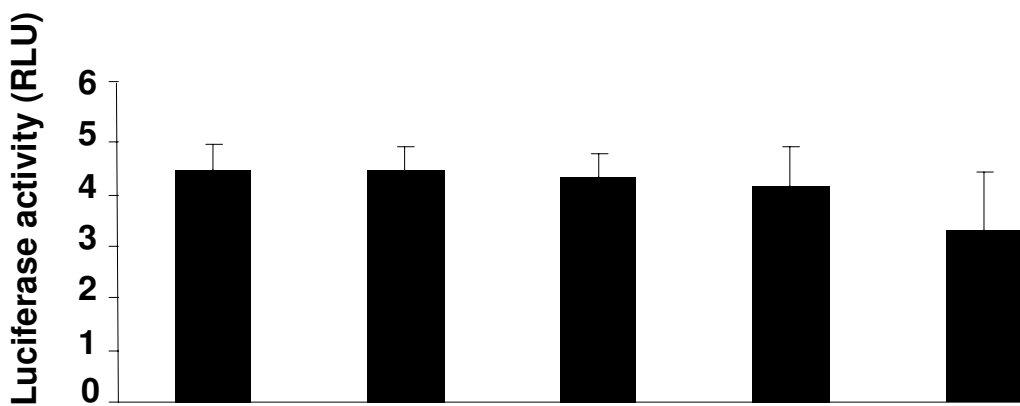

Jurkat E6.1/

pHTLV-Luc

$+$

$+$

$+$

$+$

$+$

C91-PL sup.

Galectin-1

$0 \mu \mathrm{M}$

$+$

$+$

$+$

$+$

$1 \mu \mathrm{M}$

$2 \mu \mathrm{M}$

$4 \mu \mathrm{M}$

\section{Figure 6}

Soluble galectin- I increases the extent of HTLV-I LTR activation in co-culture assay. Jurkat cells were transfected with $15 \mu \mathrm{g}$ of pHTLV-Luc and cultured for 24 hours. The transfected cells were then incubated for an additional 24 hour with an equal number of HTLV-I-infected C9I-PL cells (A) or supernatant of C9I-PL cells $(\mathbf{B})$ in the presence of galectin-I added at various concentrations with or without lactose $(50 \mathrm{mM})$. The cells were lysed 24 hours after co-culture and luciferase activities were measured. The results represent three independent co-culture assays and are expressed as the mean luciferase activity value $+/$ - standard deviations $(* p<0.05$; **p $<0.0$ I). 
NF- $\kappa B$ activators, we have shown that CREB, SRF and NF$\kappa \mathrm{B}$ are not involved in Tax-induced galectin-1 expression. This was surprising given that the Tax mutant TaxM22, which is deficient for the activation of NF- $\mathrm{BB}$, was less efficient in activating galectin-1 expression when compared to wild-type Tax. However, no typical NF- $\kappa B$ binding consensus sequences have been identified in the galectin-1 promoter region tested in this study. In this regard, it should be noted that Tax M22 has been demonstrated to be deficient for the activation of another transcription factor namely NFAT $[68,69]$. In addition, as the galectin- 1 promoter has eight Sp1-potential sites in its $1.2 \mathrm{kbp}$ region, six of which are shared with the $0.5 \mathrm{kbp}$ region, Sp1 might be such a potential transcription factor. Indeed, it has been shown that Tax can interact with $\mathrm{Sp} 1$ and the resulting complex is important for the transactivation of PTHrP P3 and GATA3 promoters [70,71]. Alternatively, Tax may indirectly induce galectin- 1 expression by maintaining a chronic activation of infected cells. In HTLV-Iinfected cells, the constitutive expression of the LTR allows a weak expression of Tax. Since activated T lymphocytes express galectin-1, it may be possible that this chronic activation of HTLV-I-infected cells by Tax indirectly induces galectin-1 expression. Finally, although our results argue for an implication of Tax, it should be stated that other HTLV-I proteins might also participate in the modulation of galectin-1 expression in infected cells as elevated galectin-1 mRNA levels were detected in the S1T cell line, which poorly expresses Tax.

As cell-free virus has very low infectivity, it is assumed that HTLV-I infection is mediated by the interaction between non-infected and infected cells, although recent evidence has demonstrated that cell-free virus can infect isolated dendritic cells [72-74]. We have previously demonstrated that galectin-1 increases HIV-1 infectivity through stabilizing the virus adsorption step [35]. In addition, galectin-1 may mediate cell-cell interaction as galectin-1 can crosslink cells. Using pseudotyped HIV-1 virions, which harbour HTLV-I gp46 envelope protein and express the luciferase reporter gene, we showed that, in both Jurkat and PBMCs, virion infection was significantly promoted in the presence of galectin-1 in a glycan binding-dependent manner, suggesting that galectin-1 increases the infectivity of HTLV-I virus particles in this system. We also used a quantitative system which mimics the mechanism involving gp46-mediated fusion in a cell-to-cell fashion. Again, galectin-1 increased this HTLV-I-induced gp46-mediated cell fusion showing that galectin-1 might also stabilize the interaction between infected and non-infected cells. Of note, no extracellular factors seemed to act upon galectin1-mediated induction of HTLV-I LTR activity in this coculture system as judged by results obtained with C91-PL supernatant. However, at this point, it cannot be dismissed that other possible gp46-independent cytoplasmic exchange modulated by galectin-1 might be taking place and lead to this upregulation of luciferase activity. Further experiments will be needed to assess this issue.

Although galectin- 1 concentrations in our infection experiments were higher than the measured levels from the supernatant of infected cells, in vivo conditions are likely to differ from our cell culture settings. Previous studies have demonstrated that lymphoid organ tissues are sites where an important number of infected Tlymphocytes are located [75-77]. Given that these tissues represent a more confined space, the concentration of galectin- 1 secreted by surrounding infected cells may represent a more appropriate environment and increase the concentration of galectin-1 to effective levels. Indeed, we have previously reported that the tonsil tissue contains 10 to $20 \mu \mathrm{M}$ galectin-1 [35]. Moreover, the transmission of HTLV-I to target cells has been shown to require the formation of a virological synapse following a cell-cell contact [7]. This synapse is formed by the binding of host molecules between the HTLV-I-infected T cells and the uninfected T lymphocytes, thereby facilitating virus transmission. Galectin-1 may be concentrated in the vicinity of this virological synapse and more favourably act upon infection. A final issue which needs to be taken into consideration in the current study relates to breast feeding, an important route for HTLV-I transmission. Lactose is an important constituent of breast milk and therefore could be suggested to hinder the action of galectin-1 during this route of HTLV-I transmission. Although one might then argue that galectin-1 is less important for this mode of transmission, it remains to be determined whether high lactose concentrations are also present at sites where initial HTLV-I infection does occur following HTLV-I transmission during breast feeding and where galectin-1 could modulate HTLV-I binding.

\section{Conclusion}

In summary, our study demonstrates a bidirectional interaction between HTLV-I and galectin-1. The data demonstrated that expression of galectin-1 was increased in chronically HTLV-I-infected cells and that this modulation of galectin-1 expression was largely attributed to the viral transactivator Tax in NF- $\kappa B$ - and CREB-independent manners. In addition, this study showed that HTLV-Iinfected cells secrete galectin- 1 at a higher level than the uninfected cells and that extracellular galectin- 1 facilitates HTLV-I infection and promotes higher levels of gp46dependent cell fusion. Given that our previous studies had demonstrated that HIV-1 is also enhanced in its infectivity by galectin-1 $[35,36]$, other retroviruses (or even other enveloped viruses) could potentially be more infectious in the presence of galectin-1. Further studies will be needed to assess the possible universal action of this $\beta$ galactoside-binding protein on the replicative cycle of various pathogens. 


\section{Competing interests}

The authors declare that they have no competing interests.

\section{Authors' contributions}

SG carried all RT-PCR analyses, transfection experiments and infection and syncytium formation assay and has drafted the manuscript. IP has conducted the ELISA assay. MO has participated in the design of the study. AV has performed the real-time RT-PCR experiments and has helped in drafting the manuscript. MJT and SS have helped in drafting and finalizing the manuscript and have provided important input on the design of the study. BB conceived the study, participated in its coordination and helped in drafting and finalizing the manuscript.

\section{Acknowledgements}

We thank Ms. Sylvie Méthot for editorial assistance. This work was performed by SG in partial fulfillment of a M.Sc. degree in the MicrobiologyImmunology Program at Laval University. MJT. is the recipient of the Canada Research Chair in Human Immuno-Retrovirology (Tier I level) and SS has been awarded a Scholarship Award (Senior level) from the Fonds de la Recherche en Santé du Québec (FRSQ). BB holds a Canada Research Chair in Human Retrovirology (Tier 2 level).

\section{References}

I. Watanabe T: HTLV-I-associated diseases. Int J Hematol 1997, 66:257-278.

2. Zaninovic V: On the etiology of tropical spastic paraparesis and human $\mathrm{T}$-cell lymphotropic virus-I-associated myelopathy. Int J Infect Dis 1999, 3:168-176.

3. Manns A, Hisada M, La Grenade L: Human T-lymphotropic virus type I infection. Lancet 1999, 353:195I-I958.

4. Derse D, Heidecker G, Mitchell M, Hill S, Lloyd P, Princler G: Infectious transmission and replication of human $\mathrm{T}$-cell leukemia virus I. Front Biosci 2004, 9:2495-2499.

5. Richardson JH, Edwards AJ, Cruickshank JK, Rudge P, Dalgleish AG In vivo cellular tropism of human $\mathrm{T}$-cell leukemia virus type I. J Virol 1990, 64:5682-5687.

6. Teruya $\mathrm{H}$, Tomita M, Senba M, Ishikawa C, Tamayose M, Miyazato A Yara S, Tanaka Y, Iwakura Y, Fujita J, et al.: Human T-cell leukemia virus type I infects human lung epithelial cells and induces gene expression of cytokines, chemokines and cell adhesion molecules. Retrovirology 2008, 5:86.

7. Igakura T, Stinchcombe JC, Goon PK, Taylor GP, Weber JN, Griffiths GM, Tanaka Y, Osame M, Bangham CR: Spread of HTLV-I between lymphocytes by virus-induced polarization of the cytoskeleton. Science 2003, 299:|7|3-17|6.

8. Fan N, Gavalchin J, Paul B, Wells KH, Lane MJ, Poiesz BJ: Infection of peripheral blood mononuclear cells and cell lines by cellfree human T-cell lymphoma/leukemia virus type I. J Clin Microbiol 1992, 30:905-910.

9. Derse D, Hill SA, Lloyd PA, Chung H, Morse BA: Examining human T-lymphotropic virus type I infection and replication by cellfree infection with recombinant virus vectors. J Virol 2001, 75:846|-8468

10. Manel N, Taylor N, Kinet S, Kim FJ, Swainson L, Lavanya M, Battini JL, Sitbon M: HTLV envelopes and their receptor GLUTI, the ubiquitous glucose transporter: a new vision on HTLV infection? Front Biosci 2004, 9:3218-324I.

II. Kinet S, Swainson L, Lavanya M, Mongellaz C, Montel-Hagen A, Craveiro M, Manel N, Battini JL, Sitbon M, Taylor N: Isolated receptor binding domains of HTLV-I and HTLV-2 envelopes bind Glut-I on activated CD4+ and CD8+ T cells. Retrovirology 2007 , 4:31.

12. Nejmeddine M, Barnard AL, Tanaka Y, Taylor GP, Bangham CR: Human T-lymphotropic virus, type I, tax protein triggers microtubule reorientation in the virological synapse. J Biol Chem 2005, 280:29653-29660.
13. Barnard AL, Igakura T, Tanaka Y, Taylor GP, Bangham CR: Engagement of specific $T$-cell surface molecules regulates cytoskeletal polarization in HTLV-I-infected lymphocytes. Blood 2005, I 06:988-995.

14. Fujisawa J, Seiki M, Sato M, Yoshida M: A transcriptional enhancer sequence of HTLV-I is responsible for trans-activation mediated by p40 chi HTLV-I. EMBO J I986, 5:7|3-7| 8.

I5. Paskalis H, Felber BK, Pavlakis GN: Cis-acting sequences responsible for the transcriptional activation of human T-cell leukemia virus type I constitute a conditional enhancer. Proc Natl Acad Sci USA 1986, 83:6558-6562.

16. Shimotohno K, Takano M, Teruuchi T, Miwa M: Requirement of multiple copies of a 21 -nucleotide sequence in the U3 regions of human T-cell leukemia virus type I and type II long terminal repeats for trans-acting activation of transcription. Proc Natl Acad Sci USA 1986, 83:8I I 2-8I I6.

17. Goren I, Semmes OJ, Jeang KT, Moelling K: The amino terminus of Tax is required for interaction with the cyclic AMP response element binding protein. J Virol 1995, 69:5806-58I I.

18. Munoz E, Israel A: Activation of NF-kappa B by the Tax protein of HTLV-I. Immunobiology 1995, 193:128-136.

19. Pise-Masison CA, Radonovich M, Mahieux R, Chatterjee P, Whiteford C, Duvall J, Guillerm C, Gessain A, Brady JN: Transcription profile of cells infected with human T-cell leukemia virus type I compared with activated lymphocytes. Cancer Res 2002, 62:3562-357I.

20. Hirabayashi J, Kasai K: The family of metazoan metal-independent beta-galactoside-binding lectins: structure, function and molecular evolution. Glycobiology 1993, 3:297-304.

21. Leffler H, Carlsson S, Hedlund M, Qian Y, Poirier F: Introduction to galectins. Glycoconj ] 2004, I 9:433-440.

22. Toscano MA, llarregui JM, Bianco GA, Campagna L, Croci DO, Salatino $M$, Rabinovich GA: Dissecting the pathophysiologic role of endogenous lectins: glycan-binding proteins with cytokinelike activity? Cytokine Growth Factor Rev 2007, 18:57-7I.

23. Hirabayashi J, Hashidate T, Arata Y, Nishi N, Nakamura T, Hirashima M, Urashima T, Oka T, Futai M, Muller WE, et al.: Oligosaccharide specificity of galectins: a search by frontal affinity chromatography. Biochim Biophys Acta 2002, I 572:232-254.

24. Hughes RC: Secretion of the galectin family of mammalian carbohydrate-binding proteins. Biochim Biophys Acta 1999, 1473: 172-185.

25. Nickel W: The mystery of nonclassical protein secretion. A current view on cargo proteins and potential export routes. Eur I Biochem 2003, 270:2109-2II9.

26. Nickel W: Unconventional secretory routes: direct protein export across the plasma membrane of mammalian cells. Traffic 2005, 6:607-6I4.

27. Baum LG, Pang M, Perillo NL, Wu T, Delegeane A, Uittenbogaart $\mathrm{CH}$, Fukuda M, Seilhamer J]: Human thymic epithelial cells express an endogenous lectin, galectin-I, which binds to core 20 glycans on thymocytes and $\mathbf{T}$ lymphoblastoid cells. J Exp Med |995, I 8 |:877-887.

28. Blaser C, Kaufmann M, Muller C, Zimmermann C, Wells V, Mallucci $L$, Pircher $H$ : Beta-galactoside-binding protein secreted by activated $T$ cells inhibits antigen-induced proliferation of $T$ cells. Eur J Immunol 1998, 28:23II-23I9.

29. Chiariotti L, Salvatore P, Frunzio R, Bruni CB: Galectin genes: regulation of expression. Glycoconj / 2004, 19:44 I-449.

30. Salvatore P, Benvenuto G, Caporaso M, Bruni CB, Chiariotti L: High resolution methylation analysis of the galectin-I gene promoter region in expressing and nonexpressing tissues. FEBS Lett 1998, 42 I: I52-158.

31. Salvatore P, Benvenuto G, Pero R, Lembo F, Bruni CB, Chiariotti L: Galectin-I gene expression and methylation state in human T leukemia cell lines. Int J Oncol 2000, I7:1015-1018.

32. Klose RJ, Bird AP: Genomic DNA methylation: the mark and its mediators. Trends Biochem Sci 2006, 3 I:89-97.

33. Salvatore P, Contursi C, Benvenuto G, Bruni CB, Chiariotti L: Characterization and functional dissection of the galectin-I gene promoter. FEBS Lett 1995, 373:159-163.

34. Kondoh N, Hada A, Ryo A, Shuda M, Arai M, Matsubara O, Kimura F, Wakatsuki T, Yamamoto M: Activation of Galectin-I gene in human hepatocellular carcinoma involves methylation-sensitive complex formations at the transcriptional upstream and downstream elements. Int J Oncol 2003, 23: I575-I583. 
35. Ouellet M, Mercier S, Pelletier I, Bounou S, Roy J, Hirabayashi J, Sato $S$, Tremblay MJ: Galectin-I acts as a soluble host factor that promotes HIV-I infectivity through stabilization of virus attachment to host cells. J Immunol 2005, I 74:4I20-4I 26.

36. Mercier S, St-Pierre C, Pelletier I, Ouellet M, Tremblay MJ, Sato S: Galectin-I promotes HIV-I infectivity in macrophages through stabilization of viral adsorption. Virology 2008, $371: 121-9$.

37. Salahuddin SZ, Markham PD, Wong-Staal F, Franchini G, Kalyanaraman VS, Gallo RC: Restricted expression of human T-cell leukemia - lymphoma virus (HTLV) in transformed human umbilical cord blood lymphocytes. Virology 1983, 129:5 I-64.

38. Popovic M, Sarngadharan MG, Read E, Gallo RC: Detection, isolation, and continuous production of cytopathic retroviruses (HTLV-III) from patients with AIDS and pre-AIDS. Science 1984, 224:497-500.

39. Popovic M, Lange-Wantzin G, Sarin PS, Mann D, Gallo RC: Transformation of human umbilical cord blood $\mathrm{T}$ cells by human $\mathrm{T}$ cell leukemia/lymphoma virus. Proc Natl Acad Sci USA 1983, 80:5402-5406.

40. Harada S, Koyanagi Y, Yamamoto N: Infection of HTLV-III/LAV in HTLV-I-carrying cells MT-2 and MT-4 and application in a plaque assay. Science 1985, 229:563-566.

41. Mills GB, Arima N, May C, Hill M, Schmandt R, Li J, Miyamoto NG, Greene WC: Neither the LCK nor the FYN kinases are obligatory for IL-2-mediated signal transduction in HTLV-Iinfected human T cells. Int Immunol 1992, 4: I233-I 243.

42. Folks T, Powell DM, Lightfoote MM, Benn S, Martin MA, Fauci AS: Induction of HTLV-III/LAV from a nonvirus-producing T-cell line: implications for latency. Science 1986, 231:600-602.

43. Hara J, Benedict SH, Champagne E, Mak TW, Minden M, Gelfand EW Comparison of $\mathrm{T}$ cell receptor alpha, beta, and gamma gene rearrangement and expression in $\mathrm{T}$ cell acute lymphoblastic leukemia. J Clin Invest 1988, 81:989-996.

44. Weiss A, Imboden J, Shoback D, Stobo J: Role of T3 surface molecules in human $\mathrm{T}$-cell activation: T3-dependent activation results in an increase in cytoplasmic free calcium. Proc Nat Acad Sci USA 1984, 81:4169-4173.

45. Kikukawa R, Koyanagi $Y$, Harada S, Kobayashi N, Hatanaka M, Yamamoto $N$ : Differential susceptibility to the acquired immunodeficiency syndrome retrovirus in cloned cells of human leukemic T-cell line Molt-4. J Virol I986, 57: I I59-II 62.

46. Lusso P, Cocchi F, Balotta C, Markham PD, Louie A, Farci P, Pal R, Gallo RC, Reitz MS Jr: Growth of macrophage-tropic and primary human immunodeficiency virus type I (HIV-I) isolates in a unique CD4+ T-cell clone (PMI): failure to downregulate CD4 and to interfere with cell-line-tropic HIV-I. J Virol I995, 69:37I2-3720.

47. Smith SD, Shatsky M, Cohen PS, Warnke R, Link MP, Glader BE: Monoclonal antibody and enzymatic profiles of human malignant T-lymphoid cells and derived cell lines. Cancer Res 1984, 44:5657-5660.

48. Pear WS, Nolan GP, Scott ML, Baltimore D: Production of hightiter helper-free retroviruses by transient transfection. Proc Natl Acad Sci USA 1993, 90:8392-8396.

49. Lahm HW, Stein S: Characterization of recombinant human interleukin-2 with micromethods. J Chromatogr 1985, 326:357-36I.

50. Matsumoto K, Shibata H, Fujisawa Jl, Inoue H, Hakura A, Tsukahara $T$, Fujii M: Human T-cell leukemia virus type I Tax protein transforms rat fibroblasts via two distinct pathways. J Virol |997, 71:4445-445।.

5I. Schwartz O, Virelizier JL, Montagnier L, Hazan U: A microtransfection method using the luciferase-encoding reporter gene for the assay of human immunodeficiency virus LTR promoter activity. Gene 1990, 88:197-205

52. Lemieux AM, Pare ME, Audet B, Legault E, Lefort S, Boucher N, Landry S, van Opijnen T, Berkhout B, Naghavi MH, et al:: T-cell activation leads to poor activation of the HIV-I clade E long terminal repeat and weak association of nuclear factor-kappaB and NFAT with its enhancer region. J Biol Chem 2004, 279:52949-52960.

53. Barbeau B, Bernier R, Dumais N, Briand G, Olivier M, Faure R, Posner $\mathrm{BI}$, Tremblay M: Activation of HIV-I long terminal repeat transcription and virus replication via NF-kappaB-dependent and -independent pathways by potent phosphotyrosine phos- phatase inhibitors, the peroxovanadium compounds. I Biol Chem 1997, 272: 12968-12977.

54. Fortin JF, Cantin R, Lamontagne G, Tremblay M: Host-derived ICAM-I glycoproteins incorporated on human immunodeficiency virus type I are biologically active and enhance viral infectivity. J Virol 1997, 71:3588-3596.

55. Bounou S, Leclerc JE, Tremblay MJ: Presence of host ICAM-I in laboratory and clinical strains of human immunodeficiency virus type $I$ increases virus infectivity and CD4(+)-T-cell depletion in human lymphoid tissue, a major site of replication in vivo. J Virol 2002, 76:1004-1014.

56. Zar JH: Biostatistical Analysis Prentice Hall, Englewoods Cliffs, NJ; 1984.

57. Harhaj EW, Good L, Xiao G, Sun SC: Gene expression profiles in HTLV-I-immortalized T cells: deregulated expression of genes involved in apoptosis regulation. Oncogene 1999, 18:134I-1349.

58. Paré ME, Gauthier S, Landry S, Sun J, Legault E, Leclerc D, Tanaka $Y$, Marriott SJ, Tremblay MJ, Barbeau B: A new sensitive and quantitative HTLV-I-mediated cell fusion assay in T cells. Virology 2005, 338:309-322.

59. Cantin R, Methot S, Tremblay MJ: Plunder and stowaways: incorporation of cellular proteins by enveloped viruses. J Virol 2005, 79:6577-6587.

60. Hildreth JE, Subramanium A, Hampton RA: Human T-cell lymphotropic virus type I (HTLV-I)-induced syncytium formation mediated by vascular cell adhesion molecule-I: evidence for involvement of cell adhesion molecules in HTLV-I biology. J Virol 1997, 71: II73-1180.

61. Valentin H, Lemasson I, Hamaia S, Casse H, Konig S, Devaux C, Gazzolo $\mathrm{L}$ : Transcriptional activation of the vascular cell adhesion molecule-I gene in T lymphocytes expressing human T-cell leukemia virus type I Tax protein. J Virol 1997, 7 I:8522-8530.

62. Ceccaldi PE, Delebecque F, Prevost MC, Moris A, Abastado JP, Gessain A, Schwartz O, Ozden S: DC-SIGN facilitates fusion of dendritic cells with human T-cell leukemia virus type I-infected cells. J Virol 2006, 80:477I-4780.

63. Daenke S, McCracken SA, Booth S: Human T-cell leukaemia/ lymphoma virus type I syncytium formation is regulated in a cell-specific manner by ICAM-I, ICAM-3 and VCAM-I and can be inhibited by antibodies to integrin beta2 or beta7. Gen Virol 1999, 80(Pt 6): 1429-1436.

64. Moriuchi M, Moriuchi H: Seminal fluid enhances replication of human T-cell leukemia virus type I: implications for sexual transmission. J Virol 2004, 78: | 2709-127II.

65. Moriuchi $M$, Inoue $\mathrm{H}$, Moriuchi $\mathrm{H}$ : Reciprocal interactions between human T-lymphotropic virus type $I$ and prostaglandins: implications for viral transmission. J Virol 2001, 75:192-198.

66. Hsu DK, Hammes SR, Kuwabara I, Greene WC, Liu FT: Human T lymphotropic virus-I infection of human $T$ lymphocytes induces expression of the beta-galactoside-binding lectin, galectin-3. Am J Pathol 1996, I48:166I-1670.

67. Shimizu T, Kawakita S, Li QH, Fukuhara S, Fujisawa J: Human T-cell leukemia virus type I Tax protein stimulates the interferonresponsive enhancer element via NF-kappaB activity. FEBS Lett 2003, 539:73-77.

68. Good L, Maggirwar SB, Sun SC: Activation of the IL-2 gene promoter by HTLV-I tax involves induction of NF-AT complexes bound to the CD28-responsive element. EMBO J 1996 , I 5:3744-3750.

69. Rivera I, Harhaj EW, Sun SC: Involvement of NF-AT in type I human T-cell leukemia virus Tax-mediated Fas ligand promoter transactivation. J Biol Chem 1998, 273:22382-22388.

70. Richard V, Nadella MV, Green PL, Lairmore MD, Feuer G, Foley JG, Rosol TJ: Transcriptional regulation of parathyroid hormonerelated protein promoter $\mathbf{P} 3$ by ETS- 1 in adult T-cell leukemia/lymphoma. Leukemia 2005, 19: I I75- I I83.

7I. Gilli SC, Salles TS, Saad ST: Regulation of the GATA3 promoter by human T-cell lymphotropic virus type I Tax protein. / Cell Biochem 2004, 93:1 I 78-II87.

72. Popovic M, Sarin PS, Robert-Gurroff M, Kalyanaraman VS, Mann D, Minowada J. Gallo RC: Isolation and transmission of human retrovirus (human t-cell leukemia virus). Science 1983 219:856-859.

73. Yamamoto N, Okada M, Koyanagi Y, Kannagi M, Hinuma Y: Transformation of human leukocytes by cocultivation with an 
adult T cell leukemia virus producer cell line. Science 1982, 21 7:737-739.

74. Jones KS, Petrow-Sadowski C, Huang YK, Bertolette DC, Ruscetti FW: Cell-free HTLV-I infects dendritic cells leading to transmission and transformation of CD4(+) T cells. Nat Med 2008, 1 4:429-36.

75. Takenouchi N, Matsuoka E, Moritoyo T, Nagai M, Katsuta K, Hasui K, Ueno K, Eizuru Y, Usuku K, Osame M, et al.: Molecular pathologic analysis of the tonsil in HTLV-I-infected individuals. J Acquir Immune Defic Syndr 1999, 22:200-207.

76. Tanaka M, Sun B, Fang J, Nitta T, Yoshida T, Kohtoh S, Kikukawa H, Hanai S, Uchida K, Miwa M: Human T-cell leukemia virus type I (HTLV-I) infection of mice: proliferation of cell clones with integrated HTLV-I provirus in lymphoid organs. J Virol 200I, 75:4420-4423

77. Kazanji M: HTLV type I infection in squirrel monkeys (Saimiri sciureus): a promising animal model for HTLV type I human infection. AIDS Res Hum Retroviruses 2000, 16: 174|-1746.

Publish with Bio Med Central and every scientist can read your work free of charge

"BioMed Central will be the most significant development for disseminating the results of biomedical research in our lifetime. "

Sir Paul Nurse, Cancer Research UK

Your research papers will be:

- available free of charge to the entire biomedical community

- peer reviewed and published immediately upon acceptance

- cited in PubMed and archived on PubMed Central

- yours - you keep the copyright 